\title{
Atwal Striae Gravidarum Score for Prediction of Perineal Tears During Vaginal Delivery: A Cross- Sectional Study
}

\author{
Ahmed M Abbas ${ }^{1 *}$, Fatma M Kamel ${ }^{2}$, Mansour A Khalifa ${ }^{1}$ and Safwat A Salman ${ }^{1}$ \\ ${ }^{1}$ Department of Obstetrics \& Gynecology, Faculty of Medicine, Assiut University, Egypt \\ ${ }^{2}$ Department of Obstetrics \& Gynecology, Abnoub Central Hospital, Egypt
}

*Corresponding author: Ahmed M Abbas, Professor, Department of Obstetrics and Gynecology, Assiut University, Women Health Hospital, Egypt.
Received Date: July 28, 2020

Published Date: August 26, 2020

\section{Abstract}

Objective: To evaluate the value of Atwal striae gravidarum (SG) score for prediction of occurrence of perineal tears (PT) during vaginal delivery.

Methods: A cross-sectional study conducted between October 2016 and April 2018 included all multiparous women presented in the active phase of labor. Assessment of SG score was done using Atwal score in the abdomen, hips, breasts and buttocks. According to the total striae score (TSS) women were classified into two groups; group (I): mild SG (TSS $\leq 12$ ) and group (II) moderate/severe SG (TSS $>12$ ). The primary study outcome was the rate of PT in both groups.

Results: The study included 421 women; 188 in group I and 233 in group II. The rate of PT was significantly higher in group II than group I ( $56.2 \%$ vs. $3.2 \%$ respectively, $p<0.001)$. Additionally, para-urethral, vaginal and cervical tears were more common in group II $(p=0.029,0.025$ and 0.047 respectively). Additionally, we found significantly higher TSS among women with PT versus those without PT $(17.07 \pm 3.56$ vs. $7.93 \pm 6.94, p$ $<0.001$ ). Multivariate regression analysis revealed that the presence of abdominal striae and the TSS $>12$ were associated with increased risk of PT.

Conclusion: Assessment of Atwal SG score could precisely predict the occurrence of PT in multiparous women during vaginal delivery.

Keywords: Striae gravidarum; Perineal tears; Vaginal delivery; Atwal score

\section{Introduction}

Perineal trauma is common during vaginal delivery varied from minor superficial mucosal lacerations to major tears involving the musculature of the perineum and rectum [1]. It can lead to a numerous complication as hemorrhage, dyspareunia, perineal abscess with subsequent rectovaginal fistula and incontinence which have a major negative effect on physical, psychological aspects and women's quality of life [2].

During vaginal delivery, the fetal head exerts considerable pressure on the vaginal and perineal tissues. This could lead to tissue tears even with a small baby and apparently easy delivery [3]. Others can deliver with intact perineum in spite of large babies or malpresentation.

Striae gravidarum (SG) are stretch marks occurred during pregnancy that may be an indicator of poor skin elasticity [4]. Women who does not have SG may have better skin elasticity and less liable to have vaginal or perineal tears during delivery [5]. SG is caused by changes in the structural connective tissue as a result of a hormonal elect on the alignment and reduced elastin and fibrillin 
in the dermis [6]. SG usually occurs on the hips, buttocks, abdomen, breasts, and thighs and usually appears after the 24th week of gestation [7]. The incidence of SG is variable ranges between $43 \%$ to $88 \%[8]$.

Scoring of SG severity was published using the numerical scoring system of Atwal [9]. This score provides a rank based on observation of four common areas of SG (abdomen, hips, buttocks, and breast). The final score for each body area ranges from 0 to 6 according to the number and color of SG. The total striae score (TSS) ranges from 0 to 24 . Women having TSS score $\leq 12$ indicated mild striae, TSS score (13-18) indicated moderate striae and TSS $>18$ indicated severe striae [9].

In a previous study by Halperin et al., 2010 reported a significant association between the degree of PT and severity of SG. Additionally, SG especially on the hips and breast predicted the occurrence of first- and second-degree PT [5].

Therefore, the aim of the present study is to determine the value of assessment of Atwal SG score in laboring women for prediction of the occurrence of PT during vaginal delivery.

\section{Patients and Methods}

The current study was a cross-sectional study conducted in a central hospital between October 2016 and April 2018. The Institutional ethical review board approved the study protocol and informed written consent was obtained from all participants after discussing the nature of the study.

\section{Eligible participants}

All multiparous women attended the reception unit of the hospital in the active phase of labor were invited to participate in the study if they met our inclusion criteria. We included women aged 18-40 years, has spontaneous onset of labor, singleton pregnancy, fetus with cephalic presentation at gestational age 37-40 weeks and estimated fetal weight by ultrasound (2500-4000gm). We excluded women with multiple pregnancy, scarred uterus, malpresentation, suspected fetal macrosomia, preterm labor, medical disorders as diabetes or hypertension and those refused to participate in the study.

\section{Recruitment}

A detailed history was taken from all women included age, parity, gestational age, residency, educational level, previous miscarriages, previous episiotomy, gestational weight gain and body mass index (BMI) was calculated for each participant.

\section{Intervention}

Inspection of the four body areas described in the Atwal SG score (abdomen, hips, buttocks, and breast) was done and the TSS was calculated for each woman [9]. The score includes the following criteria (a) the number of $S G$ at each body site $(0=$ no striae signs, $1=1-4$ striae, $2=5-10$ striae, $3=$ more than 10 striae) and (b) the color of the SG which ranges from pale to purple $(0=$ no redness, $1=$ pink, $2=$ dark red, 3 =purple). The final score for each body site, relating to number and color, ranges from 0 to 6 . Accordingly, the TSS ranges from 0 to 24. Women having TSS score up to 12 were considered to be having mild SG, TSS score (13-18) indicated moderate SG and TSS more than 18 were considered to be having severe SG.

According to the TSS, women were classified into two groups:

Group (I): women with no or mild SG $(\mathrm{TSS} \leq 12)$

Group (II): women with moderate or severe SG (TSS >12)

All study participants were followed until the second stage of labor using the portogram. All women were delivered by the same obstetrician through slow assisted delivery of fetal head with perineal support. Examination of the birth canal after delivery of the placenta with the active method was done. Any perineal tear was documented as regards the degree, location, number and length. The length of perineal tear was measured by a metal graduated and sterilized ruler. Presence of any other vaginal or cervical tears was recorded. Additionally, the neonatal data (Apgar score, weight, admission to pediatric intensive care unit) was recorded.

\section{Study outcomes}

The primary outcome was the difference in the rate of PT between both groups. Secondary outcomes included the rate of perineal tears according to each degree, number and length of perineal tears, the rate of para-urethral, vaginal and cervical tears in both groups.

\section{Statistical analysis}

Data were collected, tabulated, statistically analyzed by computer using SPSS version 22 (SPSS Inc., Chicago, IL), two types of statistics were done: Quantitative data were expressed as the mean, and standard deviation (SD). Qualitative data were expressed as frequencies and percentage. Normality of the quantitative variables was assessed using the Kolmogorov-Smirnov test. Chisquare ( $\mathrm{x} 2$ ) and independent t-test were used to compare both groups if the data were normally distributed. Otherwise, MannWhitney and Fisher's exact tests were used. A multivariate logistic regression model was performed for the predictors of occurrence of PT including, presence of SG at each body site, parity $>3$, BMI $>30$ $\mathrm{Kg} / \mathrm{m} 2$, duration of second stage of labor $>5$ minutes, and TSS $>12$. P-value $<0.05$ was considered statistically significant.

Receiver operating characteristics (ROC) curve was performed to detect the best cut-off value for Atwal score for prediction of PT generally, and 3rd, 4th degree PT specifically. The best cut-off on the ROC curve has the highest true positive rate together with the lowest false positive rate. 


\section{Results}

Five hundred twenty-three women were approached to participate in the study. We excluded 41 cases as they did not meet the inclusion criteria. The remaining 482 women were classified according to TSS into two groups: group (I) included 217 women with TSS $\leq 12$ and group (II) included 265 women with TSS $>12$. Twenty-nine women in group (I) and 32 women in group (II) were excluded from the final analysis as they did not deliver vaginally. Therefore, 188 women in group (I) and 233 women in group (II) were included in the final analysis (Figure 1).

The mean age of the study participants was $26.26 \pm 4.6$ years. The mean parity was $2.84 \pm 1.7$ and the mean gestational age at inclusion was $38.31 \pm 1.52$ weeks. SG were present in $88.1 \%$ of the study participants. The mean TSS of the whole participants was $10.91 \pm 7.41$. Of the included 421 women, 50 women (11.9\%) had no striae, while 138 (32.6\%), 159 (37.8\%) and 74 (17.7\%) women had mild, moderate and severe striae, respectively. The most common site of SG was the abdomen (85.7\%); other sites were hips (63.9\%), buttocks (57.7\%) and breasts (49.2\%).

No statistically significant difference between the baseline characteristics of both study groups (Table 1). The duration of second stage was quite similar in both study groups ( $5.05 \pm 1.24$ vs. $5.21 \pm 1.14 \mathrm{~min}, \mathrm{p}=0.175$ ). No difference between both study groups regarding the neonatal birth weight $(\mathrm{p}=0.945)$, Apgar score at 5 minutes $(p=0.072)$, and the need for pediatric intensive care unit admission ( $p=0.307)$ (Table 1).

Regarding the study outcomes, the overall incidence of PT was significantly higher in group II than group I (56.2\% vs. $3.2 \%$ respectively, $\mathrm{p}<0.001)$. Similarly, the incidence of the four degrees of PT was significantly higher in group II. Additionally, paraurethral, vaginal and cervical tears were more common in group II with statistically significant difference $(p=0.029,0.025$ and 0.047 respectively). PT occurred in group II were lengthier than group I $(\mathrm{p}=0.016)$. Multiple tears were more common in group II (41 cases vs. none) in group I ( $\mathrm{p}<0.001)$ (Table 2).

Table 1: The baseline characteristics of the study participants according to the total striae score.

\begin{tabular}{|c|c|c|c|}
\hline Characteristics & Group I $(T S S \leq 12)(n=188)$ & Group II $(T S S>12) \quad(n=233)$ & P-value \\
\hline Age (years) ${ }^{\#}$ & $27.92 \pm 4.94$ & $26.95 \pm 3.81$ & 0.25 \\
\hline Parity ${ }^{\#}$ & $3.34 \pm 1.76$ & $3.44 \pm 1.53$ & 0.129 \\
\hline Gestational age (weeks) ${ }^{\#}$ & $38.76 \pm 1.09$ & $38.54 \pm 1.33$ & 0.071 \\
\hline \multicolumn{4}{|c|}{ Residence, n (\%) } \\
\hline Urban & $11(5.9)$ & $10(4.3)$ & 0.505 \\
\hline Rural & 177 (94.1) & 223 (95.7) & \\
\hline \multicolumn{3}{|c|}{ Education, n (\%) } & \\
\hline Illiterate & $30(16)$ & $43(18.5)$ & \\
\hline Primary & $106(56.4)$ & $136(8.4)$ & 0.081 \\
\hline Secondary & $40(21.2)$ & $49(21)$ & \\
\hline University & $12(6.4)$ & $5(2.1)$ & \\
\hline Previous miscarriages, n (\%) & $30(16)$ & $48(20.6)$ & 0.57 \\
\hline Previous episiotomy, n (\%) & $132(70.2)$ & $168(72.1)$ & 0.421 \\
\hline Gestational weight gain $(\mathrm{Kg})^{\#}$ & $8.43 \pm 2.19$ & $8.21 \pm 2.11$ & 0.162 \\
\hline $\mathrm{BMI}\left(\mathrm{Kg} / \mathrm{m}^{2}\right)^{\#}$ & $27.43 \pm 3.59$ & $27.86 \pm 3.31$ & 0.32 \\
\hline
\end{tabular}

SG; striae gravidarum, TSS; total striae score, BMI; body mass index

\#Data are presented as mean \pm standard deviation

Table 2: The primary and secondary outcomes of both study groups.

\begin{tabular}{|c|c|c|c|}
\hline Outcomes & Group I $($ TSS $\leq 12) \quad(n=188)$ & Group II (TSS > 12) & P-value \\
\hline Perineal tears & $6(3.2)$ & $131(56.2)$ & $<0.001^{*}$ \\
\hline $1^{\text {st }}$ degree perineal tears & $2(1.1)$ & $60(25.8)$ & $<0.001^{*}$ \\
\hline $2^{\text {nd }}$ degree perineal tears & $1(0.5)$ & $52(22.3)$ & $<0.001^{*}$ \\
\hline $3^{\text {rd }}$ degree perineal tears & 0 & $9(3.9)$ & $0.005 *$ \\
\hline $4^{\text {th }}$ degree perineal tears & $3(1.6)$ & $12(4.2)$ & $<0.001^{*}$ \\
\hline Para-urethral tears & $1(0.5)$ & $9(3.9)$ & $0.029^{*}$ \\
\hline Vaginal tears & 0 & $7(2.4)$ & $0.025^{*}$ \\
\hline
\end{tabular}




\begin{tabular}{|c|c|c|c|}
\hline Cervical tears & $1(0.5)$ & $8(3.4)$ & $0.047^{*}$ \\
\hline Length of perineal tears $(\mathrm{cm})^{\#}$ & $2.93 \pm 1.73$ & $5.21 \pm 2.36$ & $0.016^{*}$ \\
\hline \multicolumn{4}{|c|}{ Number of perineal tears } \\
\hline Single tear & $6(100)$ & $90(68.7)$ & \multirow{3}{*}{$<0.001^{*}$} \\
\hline Two tears & 0 & $37(28.2)$ & \\
\hline Three tears & 0 & $4(3.1)$ & \\
\hline
\end{tabular}

SG; Striae Gravidarum, TSS; Total Striae Score, *Statistically significant difference

All data are presented as number (\%)

\#Variables are presented as mean \pm standard deviation

Table 3: Multivariate regression analysis of the risk factors for development of perineal tears.

\begin{tabular}{|c|c|c|c|c|}
\hline Factors & Standard error (SE) & Odds Ratio (OR) & 95\% Confidence Interval & P-value \\
\hline Breast striae & 0.509 & 0.572 & $0.211-1.55$ & 0.272 \\
\hline Buttocks striae & 0.606 & 0.443 & $0.174-1.798$ & 0.204 \\
\hline Hips striae & 0.513 & 2.674 & $0.978-7.309$ & 0.055 \\
\hline Abdomen striae & 1.045 & 10.315 & $1.33-79.968$ & $0.026^{*}$ \\
\hline Second stage duration & 0.446 & 1.897 & $0.792-4.544$ & 0.151 \\
\hline TSS $>12$ & 0.715 & 12.924 & $3.183-52.476$ & $0.000^{*}$ \\
\hline
\end{tabular}

TSS; Total Striae Score, *Statistically significant difference

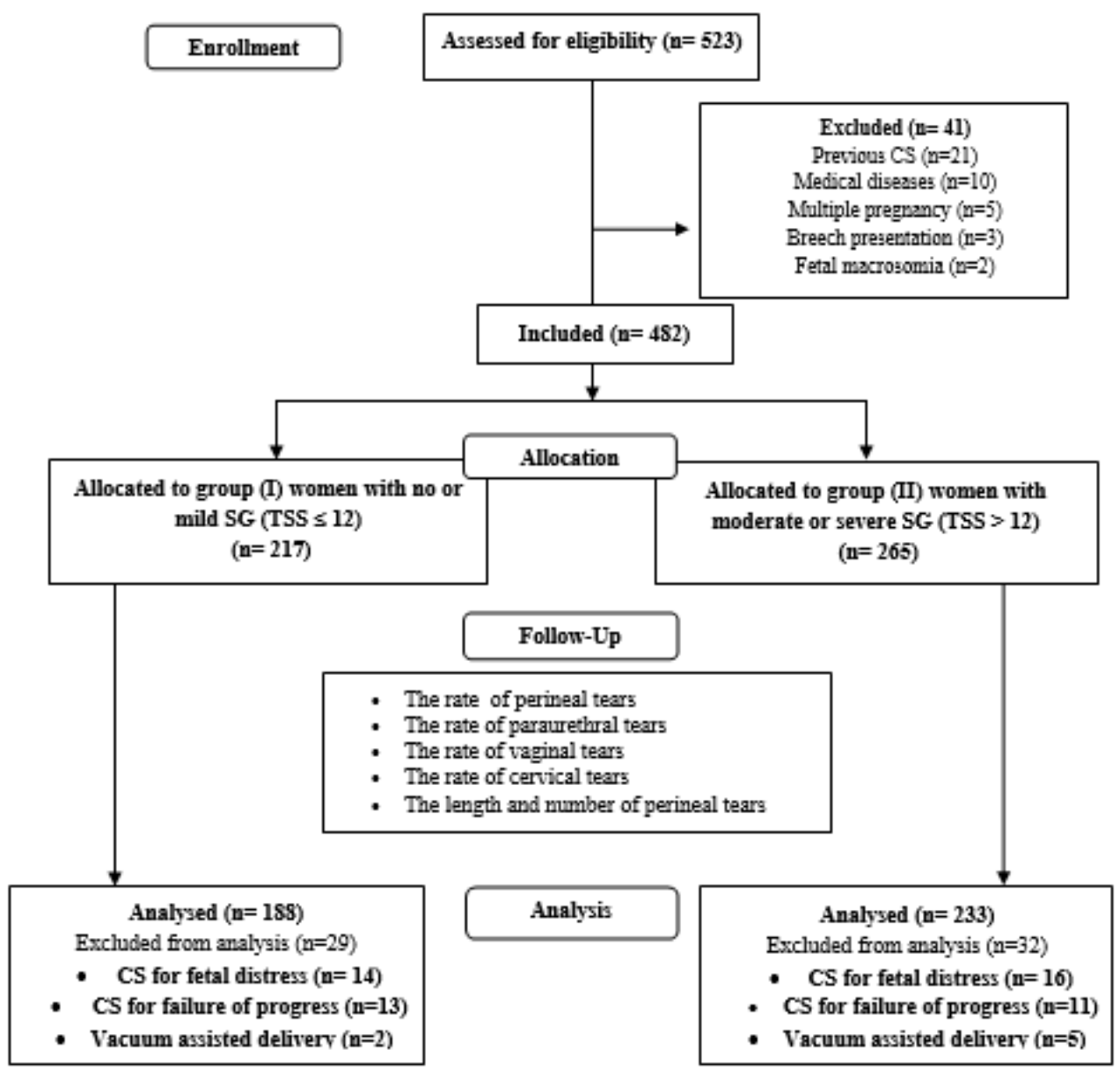

Figure 1: The study flowchart. 


\section{No perineal tears $\quad$ Perineal tears}

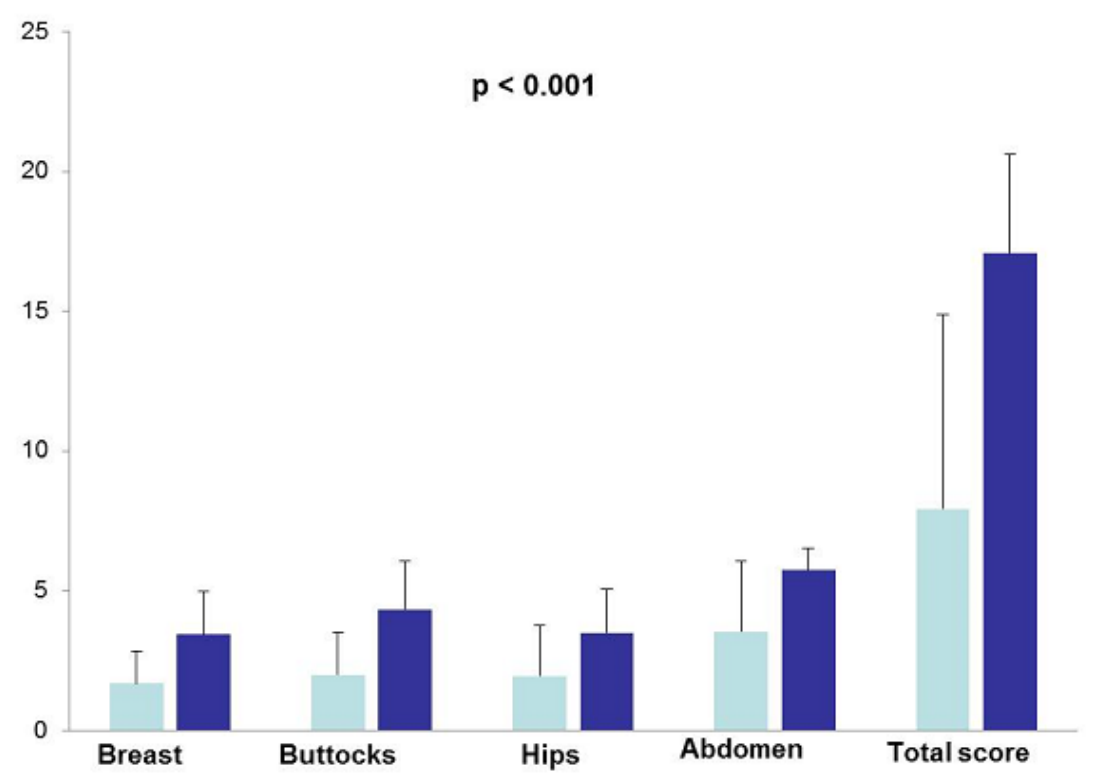

Figure 2: Differences between striae scores in women with and without perineal tears.

Perineal tears occurred in 137 (32.5\%) women of the whole participants. We found significantly higher TSS among women with PT as compared with women without PT $(17.07 \pm 3.56$ vs. $7.93 \pm 6.94$, $\mathrm{p}<0.001$ ). Figure 2 compares SG scores at each body site as well as for the TSS among women with and without PT.

Table 3 illustrates the results of multivariate logistic model of predictors of PT. According to the results of multivariate regression analysis, presence of abdominal striae and the TSS $>12$ were associated with increased risk of spontaneous PT during vaginal delivery. Therefore, they are considered as significant predictors of PT. Pregnant women with abdominal striae had 10.3 times risk of $\mathrm{PT}$ in comparison to those without abdominal striae $(\mathrm{RR}=10.315$, 95\%CI: 1.33 - 79.968; $p=0.026)$. Other sites of striae were not associated with increased risk of PT. Pregnant women with TSS $>12$ had 12.9 times risk of PT in comparison to those with TSS $\leq 12$ ( $R R=12.924$, 95\%CI: 3.183- 52.476; $p=0.000$ ). The duration of the second stage was not associated with increased risk of development of PT.

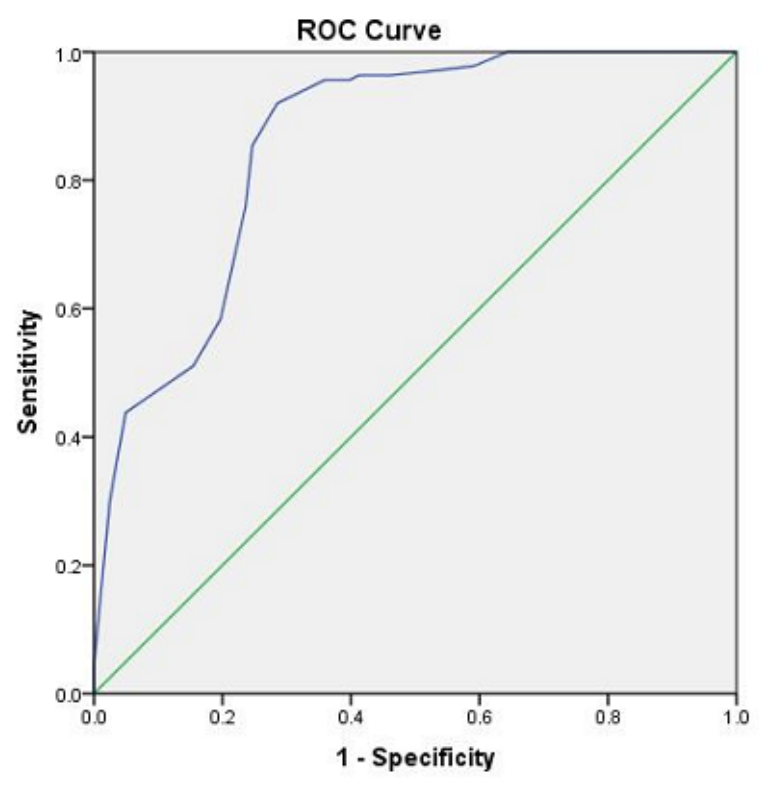

Diagonal segments are produced by ties.

Figure 3: Receiver operating characteristic curve analysis of the predictive value of total striae score for prediction of perineal tears at delivery. 


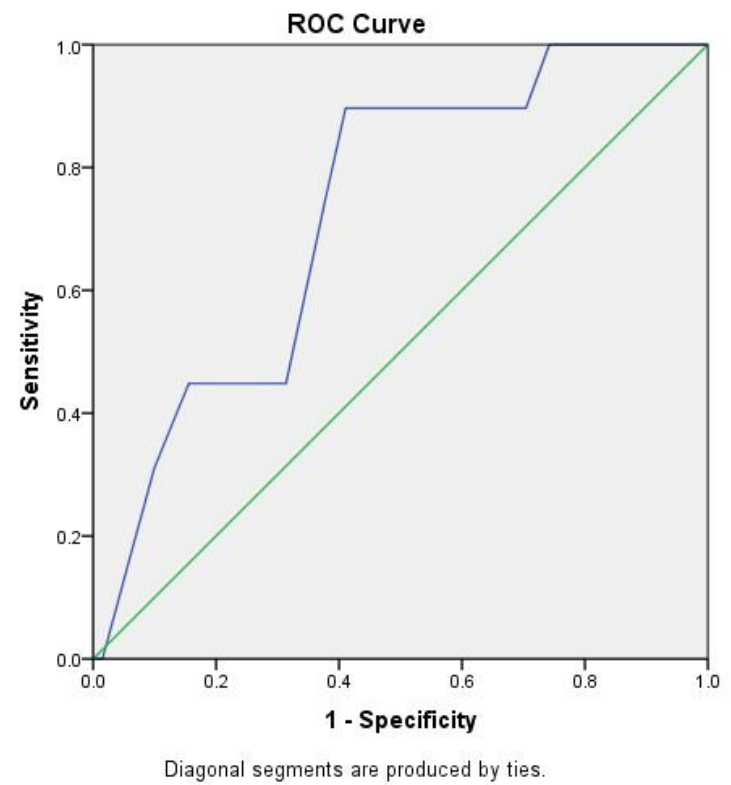

Figure 4: Receiver operating characteristic curve analysis of the predictive value of total striae score for prediction of $4^{\text {th }}$ degree perineal tears at delivery.

On ROC analysis (Figure 3), the area under the curve (AUC) for prediction of PT at vaginal delivery based on the TSS (AUC $=0.857$, $\mathrm{P}=0.000,95 \% \mathrm{CI}: 0.822-0.892)$. The ROC curve shows that the best cut off value using the TSS was $\geq 14$ with $92 \%$ sensitivity (95\%CI: 84.8-96.5) and 71.5\% specificity (95\%CI: 64.8-77.5) for prediction of PT with an overall accuracy of 78.2\% (95\%CI: 73.1-82.7).On ROC analysis (Figure 4), the AUC for prediction of 3rd\&4th degree PT at vaginal delivery based on the TSS $(\mathrm{AUC}=0.728, \mathrm{P}=0.000,95 \% \mathrm{CI}$ : 0.647-0.808). The ROC curve shows that the best cut off value using the TSS was $\geq 15$ with $89.7 \%$ sensitivity (95\%CI: 82.3-94.8) and 59 $\%$ specificity (95\%CI: 48.7-68.7) for prediction of 3rd \& 4th degree PT with an overall accuracy of 74.9\% (95CI: 68.4-80.6).

\section{Discussion}

In the present study, assessment of SG by Atwal score could significantly predict the occurrence of PT during vaginal delivery in multiparous women.

The prediction of PT at vaginal delivery has been studied several times in the Literature. Multiple risk factors have been reported including primiparity, advanced age, higher BMI, African ethnicity, gestational age $\geq 40$ weeks, longer second stage, nonsmoking, instrumental delivery, higher neonatal birth weight [10-13]. All of these variables may serve as predisposing risk factors, but none of them are pathophysiological similar to PT. Rather than using such parameters as risk factors for PT, similar connective tissue disorders such as SG may serve as a promising risk factor for the prediction of PT. Women with SG should be informed about their risk of developing PT.

The prevalence of SG in the present study (88.1\%) was higher than previous studies as Wahman et al. [14] study who reported a rate of 53.6\% among 168 American women, and Lerdpienpitayakul et al. [15] who reported a rate of $68.6 \%$ among 272 Thailandian women. However, it was nearly similar to other studies which found rates of $82.8 \%$ among a cohort of 587 Iranian women [16]. These data reflected that racial differences could affect the presence of SG. The high prevalence of SG in our study could be attributed to the characteristics of the study participants as all of them were multipara and young age $[6,17]$. The mean age of our study participants was $26.26 \pm 4.6$ years. Halperin et al. reported that younger maternal age was significantly associated with SG [5]. Women with SG were younger than women without SG $(26.74 \pm 3.57$ vs. $29.29 \pm 4.40$ years respectively, $p=0.005$ ). This could be attributed to the pregnancy hormones induced age dependent responses of the maternal skin. Younger women connective tissue has more collagen with less cross-linking of collagen; therefore, it is more liable to partial tearing that occurs due to the stretch associated with SG formation [18].

In order to evaluate the severity of SG, two main scoring systems were reported in the literatures, Atwal's score system [9], and Davey's score [19]. In Davey's score, SG was evaluated only in the abdomen by calculating the number of striae in the four quadrants [19]. On the other hand, Atwal's score depends on both the number and color of striae at four body sites; abdomen, breasts, hips and buttocks. Therefore, we used Atwal's score for our study because we supposed that it is more accurate in evaluation of SG.

The incidence of PT in the present study was $32.5 \%$. This was similar to Halperin et al. study (34\%) [5], but higher than Sereshti and her colleagues' study (14.5\%) [16]. We found a significantly higher TSS among women with PT versus those without PT 
$(17.07 \pm 3.56$ vs. $7.93 \pm 6.94, \mathrm{p}<0.001)$. This finding coincides with Halperin et al. study in which TSS was $3.60 \pm 0.39$ among women with tears versus $2.31 \pm 0.23$ among those without tears $(p=0.003)$ [5]. Our results show significantly higher rate of moderate/severe SG among women with PT versus no tears $(95.6 \%$ vs. $35.9 \%$, respectively, $\mathrm{p}<0.001)$. Similarly, Kapadia et al. reported a higher rate of moderate/severe striae among same group versus those with no tears (70\% vs. $40.7 \%$, respectively, $\mathrm{p}=0.001$ ) [3].

In our study, the rate of 3rd and 4th degree PT (Obstetric anal sphincter injuries [OASIS]) was significantly higher in women with moderate/severe SG than those with no/mild SG ( $\mathrm{p}=0.005,<0.001$ respectively). This was matched with Halperin et al. study that reported a significant association between SG severity and OASIS severity $(\mathrm{p}=0.025)[5]$.

What is new in our study that we evaluated the rate of paraurethral, vaginal and cervical tears in women with high TSS Moreover, the length and number of PT was not reported before in previous studies nor correlated with SG. We found significantly higher rate of para-urethral, vaginal and cervical tears in women with high TSS $>12$ ( $\mathrm{p}=0.029,0.025$ and 0.047 respectively). Additionally, PT occurred in those women were lengthier $(\mathrm{p}=0.016)$ and multiple $(\mathrm{p}<0.001)$ than women with no/mild SG. This confirms the hypothesis that women with severe SG have poor elasticity of tissue everywhere; therefore, tears are common in any lower genital tract tissue if stretched.

According to our logistic regression analysis, presence of abdominal striae and high TSS $>12$ were significant predictors of PT (RR=10.315, 95\%CI: 1.33-79.968; $p=0.026$ and $R R=12.924$, 95\%CI: 3.183- 52.476; p=0.000 respectively). Similarly, Halperin et al. found TSS was an independent significant predictor for perineal tears risk (RR=1.079, 95\%CI: 1.012-1.151; $\mathrm{p}=0.021$ ) [5]. Additionally, Lins et al. [12] reported that having a SG score $\geq 4$ according to Davey score was associated with increased risk of PT during delivery (RR=1.14; 95\%CI: 1.00-1.30; $\mathrm{p}=0.04)$. Keeping with our results, Kapadia et al. reported that the only predictors of PT that were found to be statistically significant in their study were the severity of SG and episiotomy given or not [3]. On the other hand, Sereshti and Deris found a significant association between breast SG score and occurrence of perineal and vaginal tears $(p=0.005)$, while SG at other body sites were not associated with PT [16].

In our study, we created a ROC curve analysis to test the accuracy of Atwal scoring system for prediction of PT for the first time in the literature. The AUC that measure how well the Atwal scoring system can predict the occurrence of the tears was (0.857). This means that the accuracy of Atwal scoring system is good (AUC= 0.80-0.90) in prediction of PT. The ROC curve shows that the best cut off value using the Atwal score was $\geq 14$ with $92 \%$ sensitivity, $71.5 \%$ specificity and $78.2 \%$ accuracy for prediction of perineal tears. Similarly, the ROC curve analysis for prediction of OASIS had an AUC $=0.728$. This means that the accuracy of Atwal scoring system is fair (AUC $=0.70-0.80$ ) in prediction of OASIS. The ROC curve shows that the best cut off value using the Atwal score was $\geq 15$ with $89.7 \%$ sensitivity, $59 \%$ specificity and $74.9 \%$ accuracy for prediction of OASIS.

The strengths of the current study are the large sample size of the study participants, inclusion of only multiparous women to avoid the confounding effect of liberal tendency for performing episiotomy in primiparous women. Additionally, for the assessment of SG as a risk factor, this was not only based on the presence or absence, but also the number, color of striae and the Atwal score are considered. Moreover, the evaluation of SG is non-invasive, simple procedure with no need for special equipment or training; therefore, it can be performed by medical interns or nurses.

In conclusion, women presented with moderate/severe striae during pregnancy should be counseled about the possibility of perineal tears during vaginal delivery. It seems likely that Atwal score $\geq 14$ is highly predictive for developing perineal tears with $78.2 \%$ accuracy. Striae scoring should be included as a part of obstetric examination in the clinical setting of women during labor. Training of medical interns and nurses for evaluation of SG by Atwal scoring system is recommended.

\section{Acknowledgement}

None.

\section{Conflict of Interest}

None.

\section{References}

1. Cichowski S, Rogers RG (2017) Managing complications of perineal lacerations. Contemporary Ob Gyn 62(9): 22.

2. Andrews V, Thakar R, Sultan AH, Jones PW (2008) Evaluation of postpartum perineal pain and dyspareunia: a prospective study. Eur J Obstet Gynecol Reprod Biol 137(2): 152-156.

3. Kapadia S, Kapoor S, Parmar K, Patadia K, Vyas M (2014) Prediction of perineal tear during childbirth by assessment of striae gravidarum score. Int J Reprod Contracept Obstet Gynecol 3(1): 208-212.

4. Hassan T, Mohsena M, Sultana A, Khondoker L, Islam S, et al. (2015) Pregnancy related skin changes and skin diseases. Bangladesh Med J 44(2): 112-116.

5. Halperin O, Raz I, Ben-Gal L, Or-Chen K, Granot M (2010) Prediction of perineal trauma during childbirth by assessment of striae gravidarum score. J Obstet Gynecol Neonatal Nurs 39(3): 292-297.

6. Osman H, Rubeiz N, Tamim H, Nassar AH (2007) Risk factors for the development of striae gravidarum. Am J Obstet Gynecol 196(1): e1-5.

7. Chang AL, Agredano YZ, Kimball AB (2004) Risk factors associated with striae gravidarum. J Am Acad Dermatol 51(6): 881-885.

8. Oakaly A, Bhimji S (2017) Stretch Marks (Striae). Stat Pearls.

9. Atwal GS, Manku LK, Griffiths CE, Polson DW (2006) Striae gravidarum in primiparae. Br J Dermatol 155: 965-969. 
10. Baghurst PA, Antoniou G (2012) Risk Models for Benchmarking Severe Perineal Tears during Vaginal Childbirth: a Cross-sectional Study of Public Hospitals in South Australia, 2002-08. Paediatric Perinatal Epidemiol 26(5): 430-437

11. Meister MR, Cahill AG, Conner SN, Woolfolk CL, Lowder JL (2016) Predicting obstetric anal sphincter injuries in a modern obstetric population. Am J Obstet Gynecol 215(3): 310.

12. Lins VM, Katz L, Vasconcelos FB, Coutinho I, Amorim MM (2018) Factors associated with spontaneous perineal lacerations in deliveries without episiotomy in a university maternity hospital in the city of Recife, Brazil: a cohort study. J Maternal Fetal Neonat Med 32(18): 3062-3067.

13. Frigerio M, Manodoro S, Bernasconi DP, Verri D, Milani R, et al. (2018) Incidence and risk factors of third-and fourth-degree perineal tears in a single Italian scenario. Eur J Obstet Gynecol Reprod Biol 221: 139-143.

14. Wahman AJ, Finan MA, Emerson SC (2000) Striae gravidarum as a predictor of vaginal lacerations at delivery. Southern Med J 93(9): 873876.
15. Lerdpienpitayakul R, Manusirivithaya S, Wiriyasirivaj B, Lorwatthanasirikul J (2009) Prevalence and risk factors of striae gravidarum in primiparae. Thai J Obstet Gynaecol 17(2): 70-9.

16. Sereshti M, Deris F (2013) Severity of Striae Gravidarum and its relationship with perineal trauma and vaginal lacerations during vaginal delivery of pregnant women referred to Hajar Hospital of Shahr-e-Kord in 2010-2011. Journal of Zanjan University of Medical Sciences and Health Services 21(89): 107-116.

17. J-Orh R, Titapant V, Chuenwattana P, Tontisirin P (2008) Prevalence and associate factors for striae gravidarum. J Med Assoc Thai 91(4): 445-451.

18. Thomas RG, Liston WA (2004) Clinical association of striae gravidarum J Obstet Gynaecol 24(3): 270-271.

19. Davey CM (1972) Factors associated with the occurrence of striae gravidarum. J Obstet Gynaecol Br Commonw 79(12): 1113-1114. 